\title{
Force Analysis of Reinforced Concrete Rectangular-sectioned Beam-supported Aqueduct
}

\author{
Dongyu $\mathrm{Ji}^{1, \mathrm{a}}$, Xidong Zhang ${ }^{2, \mathrm{~b}}$ \\ ${ }^{1}$ Hunan Urban Construction College, Xiangtan, Hunan Province 411101, P.R. China \\ ${ }^{2}$ CPI Pingdingshan Luyang Power Generation Co., Ltd, Pingdingshan, Henan Province 467312, P.R. \\ China \\ ahnjdy@126.com, b15396394@qq.com
}

Keywords: Baochuan aqueduct, Finite element method, Force analysis, Analysis paths.

\begin{abstract}
This paper adopts finite element method to carry out simulation analysis for Baochuan reinforced concrete rectangular-sectioned beam-supported aqueduct. Deducing variation law of the aqueduct's stress and displacement in construction process and operational process. Analysis results show that, Baochuan reinforced concrete aqueduct structure is reasonable, it meets the requirements for design.
\end{abstract}

\section{Project summary}

Baochuan aqueduct is located main canal of Baochuan electric pumping station, which is located Huangshan city in Anhui province. The aqueduct crosses HangHui highway, design flow rate is $0.52 \mathrm{~m}^{3} / \mathrm{s}$, longitudinal slope is $1 / 500$, overall length is $120 \mathrm{~m}$. Aqueduct structure is simply beam-supported aqueduct, aqueduct is reinforced concrete structure, section of aqueduct is rectangular. Span of aqueduct is $10 \mathrm{~m}$, aqueduct is placed on reinforced concrete single bent or double bent, maximum height of the bent is $23 \mathrm{~m}$, foundation of the bent is hard soil. Aqueduct clear wide is $0.8 \mathrm{~m}$, clear height is $0.68 \mathrm{~m}$, side wall thickness is $0.1 \mathrm{~m}$, baseplate thickness is $0.12 \mathrm{~m}$, longitudinal beam's section size is $0.1 \mathrm{~m} \times 0.08 \mathrm{~m}$. Aqueduct's design level is $0.5 \mathrm{~m}$, maximum level is $0.58 \mathrm{~m}$.

\section{Calculation Model}

Model Parameters. Concrete strength grade of Baochuan aqueduct is C20, elastic modulus $\mathrm{E}_{1}=25.5 \mathrm{GPa}$, Poisson ratio $\mu_{1}=0.167^{[1]}$, density $\gamma_{1}=25 \mathrm{kN} / \mathrm{m}^{3}$. Concrete strength grade of the bent is $\mathrm{C} 15$, elastic modulus $\mathrm{E}_{2}=22 \mathrm{GPa}$, Poisson ratio $\mu_{2}=0.167$, density $\gamma_{2}=25 \mathrm{kN} / \mathrm{m}^{3}$. Foundation of the bent is clay, elastic modulus $\mathrm{E}_{1}=50 \mathrm{MPa}^{[2]}$, Poisson ratio $\mu_{1}=0.31$.

Model Element. The aqueduct structure model is divided by eight nodes isoparametric block element. The element is often applied to three-dimensional model of entity structure, it has plasticity, creep, expansion, stress rigidization, large deformation and large strain characteristics. The element has eight nodes, each node has three translational degree of freedoms ${ }^{[3]}$. Aqueduct structure finite element calculation model is shown in Fig.1.

Calculation Cases. Considering mechanical characteristics of the aqueduct structure in construction and operating process ${ }^{[4]}$, researching three calculation cases as follows. Case 1 , aqueduct weight; case 2 , aqueduct weight and design level $(0.5 \mathrm{~m})$; case 3 , aqueduct weight and maximum level $(0.58 \mathrm{~m})$.

\section{Aqueduct Structure Analysis}

Analysis Paths. When finite element analysis for Baochuan reinforced concrete beam-supported aqueduct is proceeded, in calculation model's one half of span's section, from aqueduct's top to bottom, eight calculation points are selected respectively along counterclockwise in the aqueduct's internal surfaces. One analysis paths are confirmed, it is aqueduct's one half of span's section. 
Because aqueduct's section is symmetrical, half aqueduct's section is researched. Stress distribution of these analysis paths are provided in the paper.

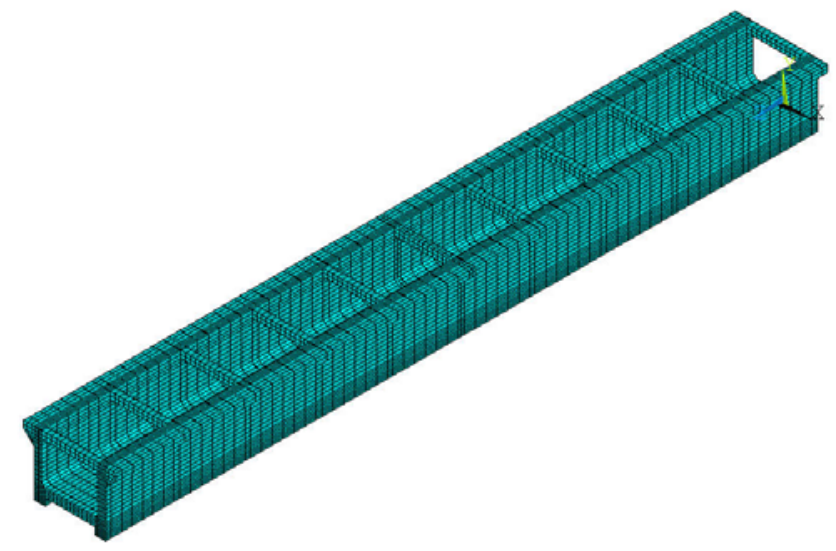

Fig.1 Aqueduct structure finite element calculation model

Stress Analysis. After three-dimensional finite element simulation analysis of reinforced concrete beam-supported aqueduct is proceeded, obtaining aqueduct's calculation point's circumferential and longitudinal stress values under various cases in construction process and operational process. The circumferential and longitudinal stress values are listed in the table 1.

Table 1. Calculation point's circumferential and longitudinal stress values on the aqueduct's analysis path under various cases(MPa)

\begin{tabular}{|c|c|c|c|c|c|c|c|c|c|}
\hline \multicolumn{2}{|c|}{ Calculation Point } & (1) & (2) & (3) & (4) & (5) & (6) & (7) & (8) \\
\hline \multirow{2}{*}{ Case 1} & $\begin{array}{c}\text { Circumferential } \\
\text { stress }\end{array}$ & -0.032 & 0.041 & 0.015 & 0.036 & 0.040 & 0.063 & -0.049 & -0.067 \\
\hline & $\begin{array}{l}\text { Longitudinal } \\
\text { stress }\end{array}$ & -0.938 & -0.917 & -0.687 & -0.092 & 0.503 & 0.676 & 0.655 & 0.649 \\
\hline \multirow{2}{*}{ Case 2} & $\begin{array}{l}\text { Circumferential } \\
\text { stress }\end{array}$ & -0.045 & 0.070 & 0.011 & 0.059 & 0.111 & 0.051 & -0.090 & -0.139 \\
\hline & $\begin{array}{c}\text { Longitudinal } \\
\text { stress }\end{array}$ & -1.368 & -1.332 & -1.003 & -0.134 & 0.744 & 0.994 & 0.950 & 0.938 \\
\hline \multirow{2}{*}{ Case 3} & $\begin{array}{c}\text { Circumferential } \\
\text { stress }\end{array}$ & -0.046 & 0.075 & -0.001 & 0.054 & 0.123 & 0.064 & -0.090 & -0.144 \\
\hline & $\begin{array}{l}\text { Longitudinal } \\
\text { stress }\end{array}$ & -1.434 & -1.394 & -1.055 & -0.141 & 0.783 & 1.046 & 0.998 & 0.985 \\
\hline
\end{tabular}

We can see from table 1, under various cases, internal surfaces circumferential stress values of aqueduct's one half of span's section are smaller, and circumferential stress values of aqueduct's side wall become compressive stress into tensile stress from aqueduct's top to bottom. Internal surfaces circumferential stress is tensile stress on both sides of aqueduct's baseplate, but internal surfaces circumferential stress is compressive stress in the middle of aqueduct's baseplate. internal surfaces longitudinal stress values of aqueduct's one half of span's section are larger, and the stress of upper section of aqueduct is compressive stress, the stress of lower section of aqueduct is tensile stress. With increase of water level, aqueduct's longitudinal stress values increase too. This is mainly because beam-supported aqueduct's force characteristics is similar with beam structure under aqueduct weight and water pressure, bending moment of midspan is maximum, bending moment of ends is minimum, so such stress distribution law is produced. Under case 3, longitudinal stress value of aqueduct is maximum, maximum longitudinal compressive stress value is $1.434 \mathrm{MPa}$, maximum longitudinal tensile stress value is $0.985 \mathrm{MPa}$.

Through finite element force analysis, we obtain contour maps of longitudinal stress of aqueduct's one half of span's section under case 1, case 2 and case 3, contour maps are shown from Fig.2 to Fig.4. 


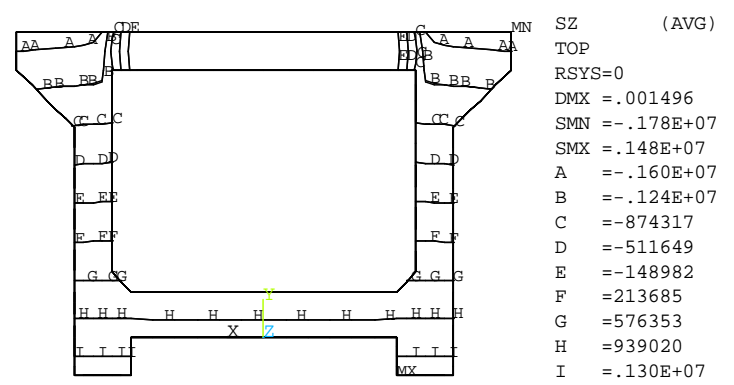

Fig.2 Contour map of one half of span section's longitudinal stress under case $1(\mathrm{~Pa})$
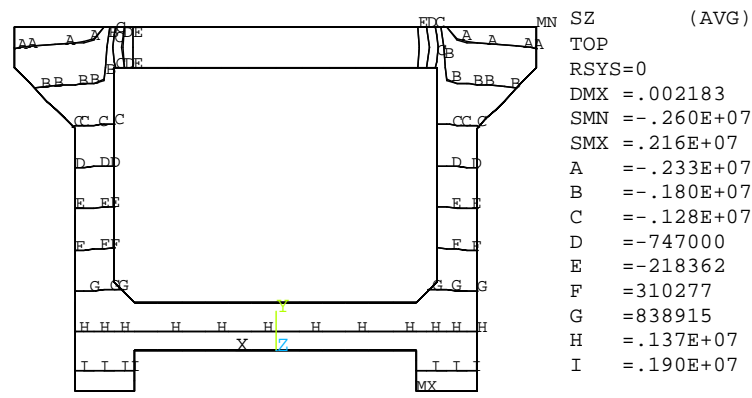

Fig.3 Contour map of one half of span section's longitudinal stress under case 2(Pa)

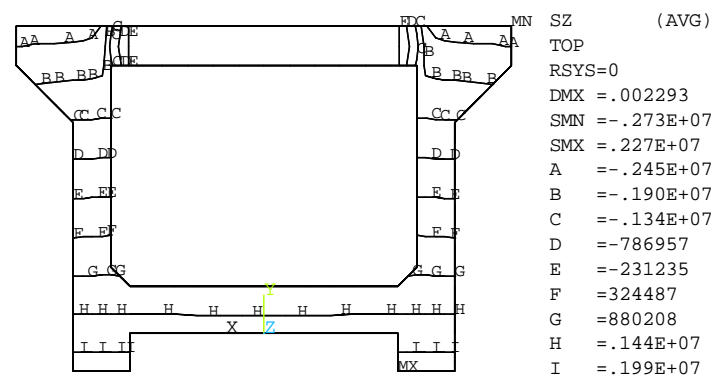

Fig.4 Contour map of one half of span section's longitudinal stress under case 3(Pa)

We can see from Fig.2 to Fig.4, contour maps of one half of span section's longitudinal stress are layered distribution, compressive stress mainly distributed in upper part of aqueduct's section, tensile stress mainly distributed in lower part of aqueduct's section. Maximum tensile and compressive stress values of Fig.3 are larger than stress values of Fig.2, this is mainly because water pressure affects. In Fig.3, aqueduct's maximum longitudinal tensile stress value is $1.99 \mathrm{MPa}$, it is located aqueduct's bottom.

Deformation Analysis. Through deformation analysis of Baochuan reinforced concrete rectangular-sectioned beam-supported aqueduct, getting aqueduct's vertical displacement variation law under various cases. The vertical displacement values of analysis paths are listed in the table 2, contour maps of one half of span section's vertical displacement under case 1, case 2 and case 3 are shown from Fig.5 to Fig.7.

Table 2. Calculation point's vertical displacement values on the aqueduct's analysis path under various cases $(\mathrm{mm})$

\begin{tabular}{|c|c|c|c|c|c|c|c|c|}
\hline Calculation Point & (1) & (2) & (3) & (4) & (5) & (6) & (7) & (8) \\
\hline Case 1 & 1.482 & 1.482 & 1.484 & 1.484 & 1.484 & 1.485 & 1.485 & 1.486 \\
\hline Case 2 & 2.160 & 2.160 & 2.162 & 2.163 & 2.164 & 2.164 & 2.166 & 2.167 \\
\hline Case 3 & 2.269 & 2.269 & 2.272 & 2.272 & 2.273 & 2.273 & 2.275 & 2.277 \\
\hline
\end{tabular}

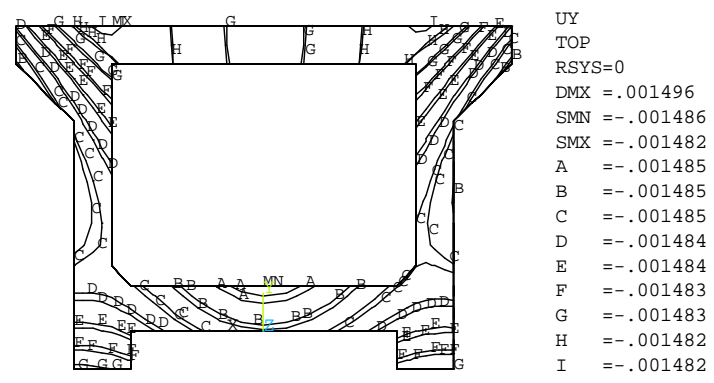

Fig.5 Contour map of one half of span section's vertical displacement under case $1(\mathrm{~Pa})$

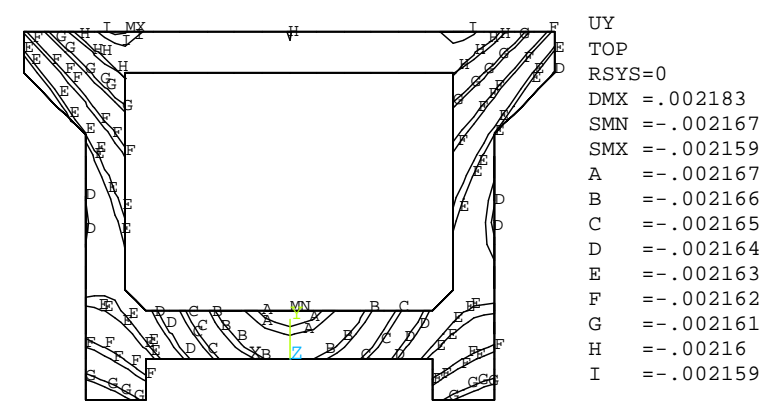

Fig.6 Contour map of one half of span section's vertical displacement under case 2(Pa) 


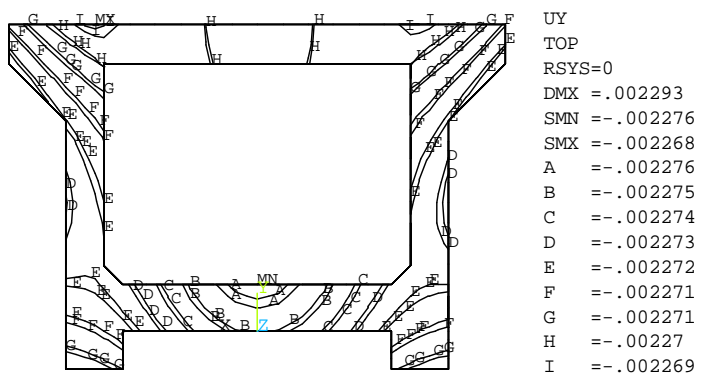

Fig.7 Contour map of one half of span section's vertical displacement under case 3(Pa)

We can see from Table 2, Fig.5, Fig.6 and Fig.7, vertical displacement values of aqueduct's one half of span section gradually increase with water level increases. But vertical displacement values of aqueduct's top and bottom differ not quite, vertical displacement values of aqueduct's bottom are slightly larger than the top, this means that aqueduct's vertical deformation values are very small in operational process.

\section{Conclusion}

From the above, design scheme of Baochuan reinforced concrete rectangular-sectioned beam-supported aqueduct is economic and reasonable, aqueduct's tensile stress values are smaller in operational process, stress values can meet strength requirements, the aqueduct structure is safe and reliable. Aqueduct's vertical displacement values are smaller, displacement values can meet rigidity requirements.

\section{References}

[1] SL191-2008: Design Code for Hydraulic Concrete Structures(China Water Conservancy and Hydropower Press, China 2008)(in Chinese)

[2] G.X. Li: Advanced Soil Mechanics(Tsinghua University Press, China 2005)(in Chinese)

[3] X.CH. Wang, M. SH: Finite Element Method Basic Principle and Numerical Method(Tsinghua University Press, China 1997)(in Chinese)

[4] H.ZH. Zhu, D.L. Chen, F.N. Guan: Aqueduct(China Water Conservancy and Hydropower Press, China 2005)(in Chinese) 